\title{
Gastrointestinal Complication of Major Abdominal Surgeries and their Effect on Total Hospital Stay
}

\author{
Authors \\ Chauhan $A^{1}$, Dutt C.K. ${ }^{2}$, Sharma $S^{3}$, Sharma $P^{4}$ \\ ${ }^{1,2}$ Associate Professor, Department of Surgery, Gajra Raja Medical College, Gwalior \\ ${ }^{3,4}$ P.G. Student, Department of Surgery, Gajra Raja Medical College, Gwalior \\ Corresponding Author \\ Dr Chandrakala Dutt \\ Associate Professor, Department of Surgery, G.R.M.C., Gwalior, MP, India
}

\begin{abstract}
Objective: This study sought to determine the influence of post operative gastrointestinal complication on the clinical outcome of the patients who underwent major abdominal surgeries.

Method: A prospective study was conducted on 100 patients who received major abdominal surgery due to emergency or elective cause admitted in surgical ward. Morbidity survey was used to evaluate the incidence of post operative complications. The influence of postoperative complications on both mortality and length of hospital stay was also assessed.

Results: Overall post operative gastrointestinal complication rate was 44\% Post operative ileus and abdominal distension accounted for most of the complications. The incidence of post operative mortality was $10 \%$ being almost thrice with emergency operations as compared to elective operation ${ }^{5}$. The mean hospital stay was nine days for uncomplicated cases, 13 days for minor complication and 30 days for complication like enterocutaneous fistula.

Conclusions: Postoperative complication are frequent disorder that are associated with poor clinical outcomes; thus structural and procedural changes along with adequate preoperative preparation with risk assessment should be done to reduce postoperative morbidity and mortality.
\end{abstract}

\section{Introduction}

Recent estimates indicate that millions of major surgical procedures are performed worldwide each year ${ }^{1}$. The high risk non cardiac surgical population represents a major global healthcare challenge. ${ }^{2,3,4,5,6,7}$. The incidence of post operative complication and death over all is low, but the subgroup of high risk patients accounts for over $80 \%$ of postoperative deaths, even though these high risk patients account for fewer than $15 \%$ of in-patient procedures ${ }^{4,6}$. Advanced age, Co- morbid disease, and major and urgent surgery are the key factors associated with increased risk ${ }^{4,6,7}$. Patients undergoing major abdominal surgeries are typical representation of such high risk patients. Despite strong evidence of their impact on poor surgical outcomes, our understanding of standards of postoperative care is limited. Many unnecessary avoidable complication can simply be eliminated by adequate preoperative work, meticulous examination and improvement of the pre-procedural medical condition of patient. Here 
comes the concept of operative risk, which is defined as sum total of abnormalities of all organ system and their interactions, those determining the outcome of an operation. The approach for minimizing operative risk should be to identify the patient at risk, identify the system at risk, prevent and protect against complications and failure of that organ system, thus improving outcome. Postoperative complications are frequent events, particularly among patients at high risk $^{8}$. These complication have both clinical effects during the immediate post operative period and long term effects on quality of life impairment and increased mortality ${ }^{9}$.

This study was designed keeping following objectives in mind:

1. To select the patients undergoing major abdominal surgery either in hepatobiliary or gastrointestinal system and urinary system.

2. Assessment of post operative course and complication in gastrointestinal system leading to their effect in increased duration of hospital stay.

\section{Material and Method}

Present work is based on 100 cases submitted to various abdominal operations in general surgery department in J.A. Group of Hospital G.R. Medical College Gwalior from 1 Jan 2012 to 31 Dec 2012. Patients of all ages and sexes have been included in this study, who have undergone any intra-abdominal procedure emergency or elective, intra or extra peritoneal however patients having operations on parieties and hernia have been excluded. Preoperatively proper history was elicited along with clinical examination followed by necessary laboratory and radiological investigation to confirm the diagnosis. Preoperative correction of anemia and dyselectrolytemia was done. Adequate gastric lavage was done in elective pyloric stenosis cases and scrupulous bowel preparation was done in cases undergoing routine large bowel surgery. All patients submitted to emergency operations received Inj. Monocef amikacin and metronidazole. Almost all cases were operated under general anaesthesia except few undergoing prostatectomy in whom spinal anaesthesia was given. A classification put forth by Gordh ${ }^{10}$ was followed to assess the degree of risk.

GRADE I RISK - A patient in whom pathology to be treated surgically is localized and is not causing systemic disturbance.

GRADE II RISK - A moderate but definite systemic disturbance caused either by condition to be treated surgically or by a preoperative complication elsewhere.

GRADE III RISK - Severe systemic disturbances from any cause.

GRADE IV RISK - A patient in extreme systemic disturbance.

\section{Observation}

Table 1 Age Distribution

\begin{tabular}{|l|c|}
\hline Age Group & No. of Cases \\
\hline Below 10 Yrs. & 5 \\
\hline 10-19 Yrs. & 9 \\
\hline 20-29 Yrs. & 30 \\
\hline 30-39 Yrs. & 21 \\
\hline 40-49 Yrs. & 10 \\
\hline 50-59 Yrs. & 13 \\
\hline 60 Yrs. and above & 12 \\
\hline
\end{tabular}

Maximum Number of cases was in age group 20-29 Yrs. youngest patient was 1 day old boy and eldest was a 90 years old male. 
Table 2 Sex Distribution

\begin{tabular}{|c|c|c|}
\hline Sex & No. of Cases & \\
\hline Males & 74 & Males outnumbered the females in ratio of $3: 1$. \\
\hline Females & 26 & \\
\hline
\end{tabular}

Table 3 Associated Conditions Present

\begin{tabular}{|l|c|}
\hline Associated Condition & No. of Cases \\
\hline Anemia/Hypoprotenemia & 42 \\
\hline Chronic Bronchitis & 06 \\
\hline Pneumonitis & 04 \\
\hline Pulmonary Tuberculosis & 03 \\
\hline Bronchial Asthma & 01 \\
\hline
\end{tabular}

Out of 100 patients, 56 had a pre-existing complications as a result of primary disease itself while a number of patients had more than one such complications. Anemia/Hypoproteinemia was the most frequent associated conditions.

Table 4 Distribution According to grade of Risk (As per Gordh's Classification 1949)

\begin{tabular}{|c|c|c|}
\hline Risk & No. of Cases & \\
\hline Grade I & 32 & Maximum number of patients were in grade II risk. The main \\
\hline Grade II & 50 & aim of this grading was to find out the relationship of \\
\hline Grade III & 16 & patient's Pre-operative status with postoperative morbidity \\
\hline Grade IV & 2 & \\
\hline
\end{tabular}

Table 5 Duration of Operation and Anaesthesia

\begin{tabular}{|l|c|c|}
\hline Duration in minutes & No. of Cases & \multirow{2}{*}{ Out of 100 operative procedures, maximum numbers 63, } \\
\hline Up to 60 & 16 & lasted 1 to 2 hours. Only 4 cases lasted more than 3 hours. \\
\hline 61 to 120 & 17 & \\
\hline 121 to 180 & 4 & \\
\cline { 1 - 2 } Max. than 180 & & \\
\hline
\end{tabular}

Table 6 Type of Anaesthesia

\begin{tabular}{|l|l|l|l}
\hline GA & 96 & General anaesthesia was administered in 96 cases. Spinal anaesthesia was \\
given only in 4 cases of BPH due to pre-existing respiratory disease. & 04 & given
\end{tabular}

Table 7 Distribution According To Types Of Surgery In Relation To Over All Morbidity and Mortality.

\begin{tabular}{|l|c|c|c|c|c|}
\hline Types of Surgery & No. of cases & With Complication & Deaths & Emergency & Elective \\
\hline Gastroduodenal & 11 & 4 & 1 & 7 & 4 \\
\hline Small Intestine/Appendix & 50 & 25 & 4 & 45 & 5 \\
\hline Large Intestine & 10 & 4 & 2 & 6 & 4 \\
\hline Hepato Biliary tract & 18 & 7 & 1 & 6 & 12 \\
\hline Urinary System & 7 & 2 & 1 & 3 & 4 \\
\hline Miscellaneous & 4 & 2 & 1 & 2 & 2 \\
\hline Total & 100 & 44 & 10 & 69 & 31 \\
\hline
\end{tabular}

Out of 100 procedures performed, 31 were operated as elective and 69 as emergency surgeries. Most of emergency surgeries was performed on small bowel and appendix while 
open vesical and prostatic operations were most frequently under-taken amongst elective procedures. $44 \%$ of cases had one or more complications in postoperative period while over all mortality was 10 .

Table 8 Incidence and pattern of gastrointestinal complication after various abdominal operations

\begin{tabular}{|c|c|c|c|c|c|c|c|c|}
\hline Types of Surgery & $\begin{array}{l}\text { No. of } \\
\text { cases }\end{array}$ & 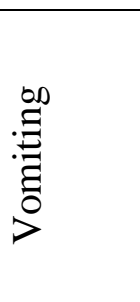 & 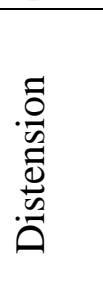 & 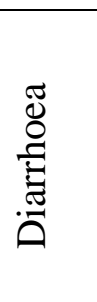 & 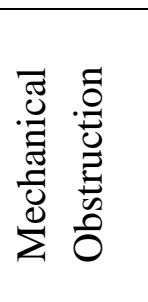 & $\stackrel{\varrho}{=}$ & 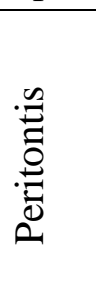 & 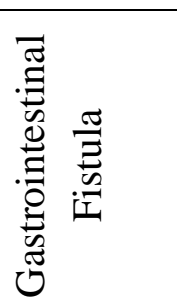 \\
\hline Gastroduodenal & 11 & 1 & 2 & 0 & 0 & 0 & 0 & 1 \\
\hline Small Intestine/Appendix & 50 & 3 & 4 & 1 & 1 & 1 & 2 & 3 \\
\hline Large Intestine & 07 & 1 & 1 & 0 & 0 & 0 & 0 & 1 \\
\hline Hepato Biliary tract & 18 & 1 & 1 & 1 & 0 & 0 & 0 & 0 \\
\hline Urinary System & 07 & 0 & 1 & 0 & 0 & 0 & 0 & 0 \\
\hline Miscellaneous & 04 & 0 & 1 & 0 & 0 & 0 & 0 & 0 \\
\hline Total & 100 & 06 & 14 & 5 & 4 & 8 & 2 & 5 \\
\hline Days of Occurrence & & $\begin{array}{l}\text { Within } \\
6 \text { hours }\end{array}$ & $\begin{array}{c}1-2 \\
\text { days }\end{array}$ & $\begin{array}{l}4-5 \\
\text { days }\end{array}$ & $\begin{array}{c}28-50 \\
\text { days }\end{array}$ & $\begin{array}{c}1-3 \\
\text { days }\end{array}$ & $\begin{array}{c}4-7 \\
\text { days }\end{array}$ & 5-20 days \\
\hline
\end{tabular}

Post operative gastrointestinal fistulae and abdominal distension accounted for more than half complications. Most complications of
Gastrointestinal tract followed after surgery on small bowel and least occured after surgery on urinary tract and appendix.

Table 9 Incidence of GI Fistulae after various types of Gastrointestinal procedures.

\begin{tabular}{|l|c|c|}
\hline Type of surgery & No. of Cases & With Fistulae \\
\hline Gastroduodenal & 11 & 1 \\
\hline Small bowel/Appdx. & 50 & 3 \\
\hline Large Bowel & 7 & 1 \\
\hline
\end{tabular}

Maximum number of gastrointestinal fistulae followed small \& large bowel surgeries.

Table 10 Complications in cases of Gastrointestinal Fistulae

\begin{tabular}{|l|c|c|}
\hline $\begin{array}{l}\text { Nature of } \\
\text { Complication }\end{array}$ & $\begin{array}{c}\text { No. of cases with } \\
\text { complication }\end{array}$ & Percentage \\
\hline $\begin{array}{l}\text { Infection } \\
\text { (wound/peritonal) }\end{array}$ & 4 & 80 \\
\hline $\begin{array}{l}\text { Fluid and electrolyte } \\
\text { imbalance }\end{array}$ & 3 & 60 \\
\hline Malnutrition & 4 & 80 \\
\hline Skin Excoriation & 1 & 20 \\
\hline Intestinal Obstruction & 2 & 40 \\
\hline Bed Sore & 2 & 40 \\
\hline Septicemia & 3 & 60 \\
\hline Thrombophlebitis & 3 & 60 \\
\hline
\end{tabular}

Out of the complication resulting directly from GI Fistulae, three main complications are infection, malnutrition and fluid and electrolyte imbalance. Table 9 also shows that amongst the complications resulting directly from fistulae, the commonest was malnutrition $(80 \%)$ followed by septicemia $60 \%$. 
Table 11 Causes of Death in 5 cases with external GI Fistulae

\begin{tabular}{|l|l|l|}
\hline Cause of death & No. of cases & Percentage \\
\hline $\begin{array}{l}\text { Infection } \\
\text { (wound/peritoneal) }\end{array}$ & 4 & $80 \%$ \\
\hline Electrolyte imbalance & 5 & $100 \%$ \\
\hline Malnutrition & 3 & $60 \%$ \\
\hline
\end{tabular}

Electrolyte imbalance was
invariably the most common
complication leading to death
resulting from GI fistulae followed
by peritonitis and malnutrition

\section{Discussion}

Out of 100 cases of various abdominal surgeries, only 56 cases were discharged without any postoperative complication. Remaining 44 patients had one or more major or minor complications. Out of them 31 cases had only one complication while 17 cases had more than are postoperative gastrointestinal complications.
The high morbidity rate is explainable due to the fact that only $1 / 3$ rd of cases belonged to "Grade I risk" according to Gordh's classification. Moreover many patients with no definitive preoperative risk were kept in "Grade II or III" risk depending on nutritional status, anemia, cachexia, obesity, senility, infection etc.

\section{Morbidity}

Table 1 : Morbidity according to grade of risk

\begin{tabular}{|l|c|c|c|}
\hline Risk & No. of cases & With complications & Percentage \\
\hline Grade I & 32 & 9 & 28.12 \\
\hline Grade II & 50 & 19 & 38.00 \\
\hline Grade III & 16 & 14 & 87.50 \\
\hline Grade IV & 2 & 2 & 100.0 \\
\hline Total & 100 & 44 & $37.00 \%$ \\
\hline
\end{tabular}

The incidence of morbidity increased steadily from "Grade 1 to Grade IV" risk. This is in accordance with Gordh's statement that the rate of complications is directly proportional to the grade of surgical risk.

Table 2 : Distribution according to grade of risk

\begin{tabular}{|c|c|c|c|c|c|c|c|c|c|c|c|}
\hline \multirow[b]{2}{*}{$\begin{array}{l}\text { Age } \\
\text { (yrs) }\end{array}$} & \multirow[b]{2}{*}{$\begin{array}{c}\text { No. } \\
\text { of } \\
\text { cases }\end{array}$} & \multirow[b]{2}{*}{ 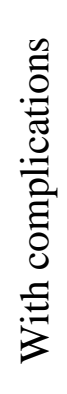 } & \multirow[b]{2}{*}{ 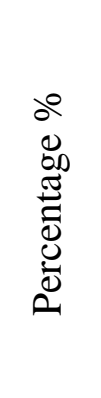 } & \multicolumn{2}{|c|}{ Gr. I } & \multicolumn{2}{|c|}{ Gr. II } & \multicolumn{2}{|c|}{ Gr. III } & \multicolumn{2}{|c|}{ Gr. IV } \\
\hline & & & & 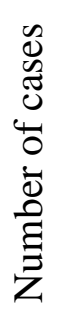 & | & 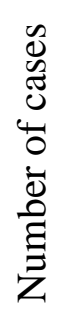 & 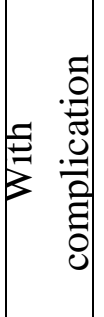 & 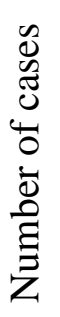 & 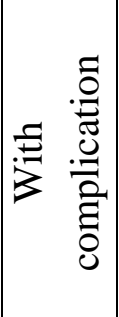 & 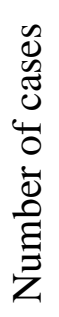 & 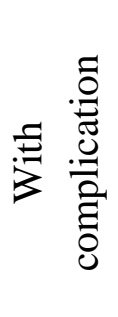 \\
\hline Below 10 & 5 & 3 & 50 & 2 & 1 & 2 & 1 & - & - & 1 & 1 \\
\hline $10-19$ & 9 & 3 & 77.7 & 5 & 1 & 2 & 1 & 2 & 1 & - & - \\
\hline $20-29$ & 30 & 10 & 68.2 & 10 & 2 & 15 & 6 & 5 & 2 & - & - \\
\hline $30-39$ & 21 & 9 & 71.8 & 6 & 2 & 13 & 5 & 2 & 2 & - & - \\
\hline $40-49$ & 10 & 6 & 83.3 & 2 & 1 & 7 & 4 & 1 & 1 & - & - \\
\hline $50-59$ & 13 & 5 & 85.3 & 3 & 1 & 8 & 3 & 3 & 1 & - & - \\
\hline 60 and above & 12 & 8 & 93.6 & 1 & 1 & 6 & 4 & 4 & 2 & 1 & 1 \\
\hline
\end{tabular}


The incidence of morbidity increases with age, being maximum in the age group of 60 years and above. However, cases in younger age group of
10-19 years also had a high morbidity as many of them belonged to "Grade III risk", which itself had a high morbidity and mortality rate.

Table 3 : Morbidity according to sex

\begin{tabular}{|l|c|c|c|c|c|c|}
\hline \multirow{2}{*}{ Risk } & \multicolumn{3}{|c|}{ Males } & \multicolumn{3}{c|}{ Females } \\
\cline { 2 - 7 } & $\begin{array}{c}\text { No. of } \\
\text { cases }\end{array}$ & $\begin{array}{c}\text { With } \\
\text { complication }\end{array}$ & $\%$ & $\begin{array}{c}\text { No. of } \\
\text { cases }\end{array}$ & $\begin{array}{c}\text { With } \\
\text { complication }\end{array}$ & $\%$ \\
\hline Grade I & 20 & 10 & 50 & 10 & 4 & 40 \\
\hline Grade II & 41 & 25 & 60.97 & 11 & 7 & 63.64 \\
\hline Grade III & 12 & 8 & 66.66 & 4 & 2 & 50 \\
\hline Grade IV & 1 & 1 & 100 & 1 & 1 & 100 \\
\hline Total & 74 & 44 & 59.46 & 26 & 14 & 53.84 \\
\hline
\end{tabular}

Sex per se does not seem to have any significant influence on the postoperative morbidity.

The incidence of morbidity was maximum after gastrointestinal operations mainly of large bowel followed by small bowel and gastroduodenal region. The nature of primary disease and the severity of operations performed on gastrointestinal tract could be possible factors responsible for highest morbidity after these operations.

Table 4 : Morbidity according to duration of operation

\begin{tabular}{|c|c|c|c|c|}
\hline $\begin{array}{l}\text { Duration in } \\
\text { minutes }\end{array}$ & $\begin{array}{l}\text { No. of } \\
\text { cases }\end{array}$ & Complication & Percentage & \multirow{4}{*}{$\begin{array}{l}\text { The patients who had longer } \\
\text { duration of surgery suffered from } \\
\text { higher percentage of morbidity } \\
\text { because of the greater severity of } \\
\text { operation and underlying pathology. }\end{array}$} \\
\hline Up to 60 & 16 & 02 & $12.5 \%$ & \\
\hline $61-120$ & 63 & 27 & $42.85 \%$ & \\
\hline More than 120 & 21 & 15 & $71.42 \%$ & \\
\hline
\end{tabular}

Table 5 : Morbidity according to urgency of operation

\begin{tabular}{|l|c|c|c|}
\hline Type of surgery & $\begin{array}{c}\text { No. of } \\
\text { cases }\end{array}$ & $\begin{array}{c}\text { With } \\
\text { Complication }\end{array}$ & Percentage \\
\hline Elective & 31 & 9 & 29.03 \\
\hline Emergency & 69 & 35 & $50.72 \%$ \\
\hline
\end{tabular}

Emergency operations had a higher rate of postoperative complications in concurrence with opinion of gordth's. It is also explained as emergency cases were high risk cases and had less time available for preoperative preparation

\section{Mortality}

There were 10 deaths out of 100 cases giving an overall mortality rate of $10 \%$.

Table 6 : Mortality according to grade of risk

\begin{tabular}{|c|c|c|c|c|c|}
\hline Risk & $\begin{array}{l}\text { No. of } \\
\text { cases }\end{array}$ & $\begin{array}{c}\text { With } \\
\text { complications }\end{array}$ & $\begin{array}{l}\text { No. of } \\
\text { deaths }\end{array}$ & Percentage & \multirow{6}{*}{$\begin{array}{l}\text { Incidence of mortality was found to be } \\
\text { directly proportional to the grade of risk. } \\
\text { In our study mortality rate was } 10 \% \text {. But } \\
\text { reported mortality rates after major } \\
\text { abdominal surgery can be a high as } \\
17 \%{ }^{13} \text {, but are usually between } 3 \% \text { and } \\
7 \% .^{14,15,16}\end{array}$} \\
\hline Grade I & 32 & 4 & - & - & \\
\hline Grade II & 50 & 29 & 03 & $10.34 \%$ & \\
\hline Grade III & 16 & 13 & 05 & $38.46 \%$ & \\
\hline Grade IV & 02 & 02 & 02 & $100 \%$ & \\
\hline Total & 100 & 44 & 10 & $22.72 \%$ & \\
\hline
\end{tabular}


Table 7 : Mortality in relation to sex

\begin{tabular}{|l|c|c|c|}
\hline Sex & $\begin{array}{c}\text { No. of } \\
\text { cases }\end{array}$ & No. of death & $\%$ \\
\hline Male & 74 & 6 & 8.23 \\
\hline Female & 25 & 4 & 15.34 \\
& & & \\
\hline
\end{tabular}

Sex per se does not seem to play an important role in postoperative mortality. This greater percentage of mortality in females (3/4th) is due to fact that maximum of them belonged to grade II, III \& IV in comparison to males, in whom only $2 / 3$ rd belong to the grade II, III and IV.

Table 8 : Mortality according to age

\begin{tabular}{|l|c|c|}
\hline Age group (yrs) & No. of cases & No. of deaths \\
\hline Below 10 & 5 & 2 \\
\hline $10-19$ & 9 & 1 \\
\hline $20-29$ & 30 & 1 \\
\hline $30-39$ & 21 & 1 \\
\hline $40-49$ & 10 & 1 \\
\hline $50-59$ & 13 & 2 \\
\hline 60 and above & 12 & 2 \\
\hline Total & 100 & 10 \\
\hline
\end{tabular}

There does not seem to be any definitive relationship between age and postoperative mortality. This ranging pattern in different age group is explainable on "grade of risk". High mortality in extremes of age group is because of the patients belonging to "grade III risk", while lowest mortality in age group 20-29 years can be explained du to maximum patients of this group belonging to "Grade I and II"

Table 9 : Mortality according to duration of operation

\begin{tabular}{|l|c|c|}
\hline Duration in minutes & No. of cases & No. of deaths \\
\hline Upto 60 & 16 & 1 \\
\hline $61-120$ & 63 & 3 \\
\hline More than 120 & 21 & 6 \\
\hline Total & 100 & 10 \\
\hline
\end{tabular}

The gravity of underlying pathology and severity of operation seem to have a direct influence upon mortality rate indirectly prolonging the duration of operation. Mortality was maximum in operations lasting for more than 2 hours.

The mortality was more in emergency operations (11.59\% - 8 out of 69 cases) and less after elective procedures $(6.4 \%-2$ out of 31 cases). Here also explanation lies in preoperative clinical status, underlying pathology severity, severity of operation and lack of adequate time for

preoperative preparation resulting in high mortality in emergency cases. It is also evident that maximum mortality was associated with small bowel surgeries followed by large bowel and gastroduodenal operations in that order.

Table 10 Cause of postoperative mortality

\begin{tabular}{|l|c|}
\hline Cause of death & No. of cases \\
\hline Gastrointestinal fistula & 4 \\
\hline Peritonitis with toxemia & 3 \\
\hline Renal failure & 2 \\
\hline Haemorrhage & 1 \\
\hline Total & 10 \\
\hline
\end{tabular}

Gastrointestinal fistula accounted for half of overall mortality due to severe electrolyte imbalance with or without sepsis. Peritonitis developed due to leak from anastomotic site, while renal failure developed due to prolonged pre-operative hypotension secondary to reactionary haemorrahge following traumatic spleen rupture.

Overall incidence of external gastrointestinal fistula was $5 \%$ in the present series. The incidence of gastrointestinal fistula following abdominal surgery in other studies have been ranging from 0 $7 \%$ to as high as $19 \%^{12}$.
There were 4 cases of small bowel and colonic fistula out of 100 abdominal operations. Anastomotic breakdown was responsible for fistula formation. This is in accordance with Edmunds et.al ${ }^{11}$ who stated that anastomotic 
breakdown is the most common cause of postoperative gastrointestinal fistula. All cases developed external gastrointestinal fistulae between 5 th-21st postoperative days. The average day of occurrence of fistula is 9th Postoperative day.

Table 11 : Mortality from Various Types of Gastrointestinal fistulae

\begin{tabular}{|l|c|c|c|}
\hline Type of fistula & $\begin{array}{c}\text { No. of } \\
\text { cases }\end{array}$ & $\begin{array}{c}\text { No. of } \\
\text { death }\end{array}$ & $\%$ \\
\hline Duodenal & 1 & 1 & 100 \\
\hline Small bowel & 3 & 2 & 66.66 \\
\hline Large bowel & 1 & 0 & 0 \\
\hline Total & 5 & 3 & $60 \%$ \\
\hline
\end{tabular}

High mortality rate $(60 \%)$ in present series is attributable to the fact that all cases to start with were bad cases belonging to "grade III risk". Mortality rate from duodenal fistula was highest followed by small and large bowel in that order. In literature, it has been reported upto $43 \%$. $^{11}$

There were 6 cases of intestinal obstruction (2 mechanical obstruction and 4 paralytic ileus) following 100 abdominal operations giving an overall incidence of $6 \%$. In cases of mechanical obstruction, primary operation was either done for bowel perforation repair or adhesiolysis. In all these cases, adhesion or bands were the cause of obstruction. Mechanical obstruction presented between 28th-50th postoperative day in present series.

Postoperative vomiting was observed in 11 cases in present series (11\%). It occurred within 6 hrs of operation and stopped within 24 hours, probably was due to after effect of anaesthesia.

Postoperative abdominal distension was noticed in 7 cases $(7 \%)$. This however excludes distension associated with ileus or mechanical obstruction. It occurred mostly in extraperitoneal procedures like prostatic surgeries, suggesting the importance of nasogastric suctions in peritoneal procedure. It was mainly gaseous appearing on 1st or 2nd postoperative day improving with conservative methods.

There was $2 \%$ incidence of diarrhoea in our study. It seemed to be of infective origin and responded to antibiotics and symptomatic measures.

Out of 100 patients, 3 (3\%) developed postoperative peritonitis due to anastomotic leakage. All the cases presented between 4th to 7 th postoperative day with high fever, abdominal distension, vomiting and absent bowel sounds.

Three (3\%) cases postoperatively developed intraperitoneal collections. It was diagnosed with postoperative ultrasonography. 2 cases developed subphrenic abscess and one developed pelvic abscess.

Amongst the miscellaneous complications, hyperpyrexia occurred in 5 cases and was contributory factory in causing death of all these patients. Enteric encephalopathy was observed in 3 cases all of which died. Other complications included jaundice, bed sores and hiccup.

The mean hospital stay was 9 days for uncomplicated cases, 13 days for minor complications and 30 days for complications like enterocutaneous fistula.

There is no single measure or "magic bullet" to decrease the postoperative complication rate or mortality after surgery. A multimodal approach is evidently needed. Applying ERAS (Enhanced Recovery After Surgery) Recommendation, ${ }^{17,18}$ perioperative goal directed infusion therapy, and hemodynamic optimisation ${ }^{19,20}$ and improving access to the intensive care or high dependency unit $^{21}$ have all shown to be of value in decreasing postoperative negative complications.

\section{Conclusion}

The gastrointestinal complication rate after major abdominal surgeries is high. These postoperative complications significantly increase the hospital stay and mortality. Gordh's grading of risk assessment reflects the increased risk of postoperative complications including mortality and can be recommended as useful preoperative indices to identify high risk patients. 


\section{References}

1. T.G. Weiser, S.E. Regenbogen, K.D. Thompson, A.B. Haynes, S.R. Lipsitz, W.R. Berry et al. An estimation of the global volume of surgery: a modelling strategy based an available data. Lancet, 372(2008), pp 139-149.

2. S.F. Jencks, M.V. Williams, E.A. Coleman. Rehospitalizations among patients in the Medicare fee-for-service program. N Engl J Med, 360(2009), pp 1418-28.

3. S.F. Khuri, W.G. Hendersen, R.G. DePalma, C. Mosca, N.A. Healey, D.J. Kumbhani. Participants in the VA National Surgical Quality Improvement Program. Determinants of long term survival after major surgery and the adverse effects of postoperative complications. Ann Surg, 242(2005), pp. 326-341.

4. S. Jhanji, B. Thomas, A. Ely, D. Watson, C.J. Hinds, R.M. Pearse. Mortality and utlisation of critical care resources amongst high-risk surgical patients in a large NHS Trust. Anaesthesia, 63(2008), pp. 695-700.

5. J. Head, J.E. Ferrie, K. Alexanderson, H. Westerlund, J. Vahtera, M. Kivimaki. Diagnosis specific sickness absence as a predictor of mortality: The Whitchall 11 prospective cohort study. $\mathrm{Br}$ Med J, 337(2008), p. a1469.

6. R.M. Pearse, D.A. Harrison, P. James, D. Watson, C. Hinds, A. Rhodes, et al. Identification and characterisation of the high risk surgical population in the United Kingdom. Crit Care, 10(2006), p. R81.

7. M. Cullinane, A.J. Gray, C.M. Hargraves, M. Lansdown, I.C. Martin, M. Schubert. The 2003 Report of the National Confidential Enquiry into Pre-operative deaths in London. NCEPOD (2003).

8. Ricciardi R, Roberts PL, Read TE, Hall JF, Marcello PW, Schoetz DJ. Which adverse events are associated with mortality and prolonged length of stay following colorectal surgery? J Gastrointest Surg. 2013;17(8):1485-93.

9. Brown SR, Mathew $\mathrm{R}$, Keding A, Marshall HC, Brown JM, Jayne DG. The impact of postoperative complications on long term quality of life after curative colorectal cancer surgery. Ann Surg 2014;259(5):916-23.

10. Gordh, T. Acta. Chir. Scand, 98:248, 1949.

11. Edmunds LH, Williams GH, Welch CE. External fistulas arising from gastrointestinal tract. Ann Surg 1960;152:445-71.

12. Seow-Choen, Tsunodo A, Nicholls RJ. Prospective randomized trial comparing anal function after hand-sewn ileo-anal anastomosis with mucosectomy versus stapled ileo-anal anastomosis without mucosectomy in restorative proctocolectomy. Br J Surg 1991;78:430-4.

13. J. Wilson, I. Woods, J. Fawcett, R. Whall, W. Dibb, C. Morris et al. Reducing risk of major elective surgery: Randomized controlled trial of preoperative optimisation. BMJ 1999;318:1099-1103.

14. Dimick JB, Cowan JA, Upchurch GR, Colletti LM. Hospital volume and surgical outcomes for elderly patients with colorectal cancer in United States. J Surg Res 2003;114:50-56.

15. AA Ghaferi, JD Birkmeyer, JB Dimick. Variation in hospital mortality associated with inpatient surgery. N Engl J Med, 361(2009), pp. 1368-75.

16. P.G. Noordzij, D. Poldermans, O. Schouten, J.J. Bax, F.A. Schreiner, E. Boersma. Postoperative mortality in Netherlands: a population-based analysis of surgery specific in adults. Anaesthesiology, 112(2010), p. 1105-1115.

17. L. Lv. Y.F. shao, Y.B. Zhou. The enhanced recovery after surgery (ERAS) pathway for patients undergoing colorectal surgery: an update of meta-analysis of 
randomized controlled trials. Int $\mathrm{J}$

Colorectal Dis. 27(2012), pp. 1549-1555.

18. C. Eskicioglu, S.S. Forbes, M.A. Aarts, A. Okranec, R.S. Mcleod. Enhanced recovery after surgery (ERAS) programs for patients having colorectal surgery: A metaanalysis of randomized trials. J Gastroint Surg. 13(2009), pp. 2321-2329.

19. M.A. Hamilton, M. Cecconi, A. Rhodes. A systematic review and meta-analysis on the use of preemptive hemodynamic interventions to improve postoperative outcomes in moderate and high risk surgical patients. Anesth Analg, 112(2011), pp. 1392-1402.

20. A. Rhodes, M. Cecconi, M. Hamilton, J. Poloniecki, J. Woods, O. Boyd et al. Goal directed therapy in high risk surgical patients: a 15 years follow up study. Intensive Care Med. 36(2010), pp. 13271332.

21. R. Bellomo, D. Goldsmith, S. Uchino, J. Buckmaster, G. Hart, H. Opdam, et al. A before and after trial of the effect of a high dependency unit on postoperative morbidity and mortality. Crit Care Resusc, 7(2005), pp. 16-21. 